\title{
Effects of intensive home visiting programs for older people with poor health status: A systematic review Ans Bouman*1, Erik van Rossum ${ }^{2,4}$, Patricia Nelemans ${ }^{1}$, Gertrudis IJM Kempen ${ }^{2}$ and Paul Knipschild ${ }^{3}$
}

\begin{abstract}
Address: ${ }^{1}$ Department of Epidemiology, Faculty of Health, Medicine and Life Sciences, Maastricht University, Peter Debyeplein 1, 6229 HA Maastricht, The Netherlands, ${ }^{2}$ School for Public Health and Primary Care (Caphri), Maastricht University, Maastricht, The Netherlands, ${ }^{3}$ Department of General Practice, Maastricht University, Maastricht, The Netherlands and ${ }^{4}$ Centre on Autonomy and Participation of the chronically ill, Zuyd University, Heerlen, The Netherlands
\end{abstract}

Email: Ans Bouman* - Ans.Nicolaides@EPID.unimaas.nl; Erik van Rossum - Erik.vanRossum@ZW.unimaas.nl; Patricia Nelemans - Patty.Nelemans@EPID.unimaas.nl; Gertrudis IJM Kempen - G.Kempen@ZW.unimaas.nl; Paul Knipschild - Paul.Knipschild@HOME.nl

* Corresponding author

Published: 3 April 2008

BMC Health Services Research 2008, 8:74 doi:10.1 186//472-6963-8-74
Received: 16 November 2007

Accepted: 3 April 2008

This article is available from: http://www.biomedcentral.com/I472-6963/8/74

(c) 2008 Bouman et al; licensee BioMed Central Ltd.

This is an Open Access article distributed under the terms of the Creative Commons Attribution License (http://creativecommons.org/licenses/by/2.0), which permits unrestricted use, distribution, and reproduction in any medium, provided the original work is properly cited.

\begin{abstract}
Background: Home visiting programs have been developed aimed at improving the health and independent functioning of older people. Also, they intend to reduce hospital and nursing home admission and associated cost. A substantial number of studies have examined the effects of preventive home visiting programs on older people living in the community; the findings have been inconsistent. The objective of this review was to assess the effectiveness of intensive home visiting programs targeting older people with poor health or otherwise with functional impairments.

Methods: A search for literature was based on included trials from four reviews on the effectiveness of home visits published after 2000 and on a database search of Cinahl, the Cochrane Central Register of Controlled Trials, Embase, Medline and PsycINFO from 200I onwards. We also manually searched reference lists from potentially relevant papers. Randomized controlled trials were included assessing the effectiveness of intervention programs consisting of at least four home visits per year, an intervention duration of 12 months or more, and targeting older people (aged 65 years and over) with poor health. Two reviewers independently abstracted data from full papers on program characteristics and outcome measures; they also evaluated the methodological quality.

Results: The search identified 844 abstracts; eight papers met the inclusion criteria. Seven trials were of sufficient methodological quality; none of the trials showed a significant favorable effect for the main analysis comparing the intervention group with the control group on mortality, health status, service use or cost. The inclusion of less-intensive intervention programs for frail older persons would not have exerted a great influence on the findings of our review.
\end{abstract}

Conclusion: We conclude that home visiting programs appear not to be beneficial for older people with poor health within the health care setting of Western countries. 


\section{Background}

Home visiting programs have been developed aimed at improving the health and independent functioning of older people. Also, they intend to reduce hospital and nursing home admission and associated cost. A substantial number of studies have examined the effects of preventive home visiting programs on older people living in the community. Since 2000 four systematic reviews [1-4], a literature review [5] and a synthesis of several reviews [6] have been published. Furthermore, a review on the effectiveness of preventive primary care outreach interventions aimed at older people was published, but this review also included trials not based on home visiting programs [7]. The reviews produced inconsistent and conflicting results. Subgroup analyses of the largest meta-analysis showed that effective home-visiting programs include multidimensional assessment, many follow-up visits and targeted people at lower risk of death [3].

A trial in the Netherlands in the 1990s showed that home visits do not seem to be useful for the general population of older people, but subgroup analyses in this study suggested benefits for older people with poor health $[8,9]$. To investigate this further, a Dutch trial by Bouman et al. was recently conducted focusing on older people with poor health at baseline [10-13]. The study could not confirm beneficial effects on health status or service use for this target group. It is possible however that these findings constituted an isolated observation. In order to make a more well-founded judgment upon the effectiveness of home visits for this group of older persons, we decided to integrate the evidence from the study by Bouman $e t$ al. with evidence from other trials. Here we publish a systematic review to investigate whether the findings from this trial have also been reported by comparable studies targeting older people with poor health, or otherwise with functional impairments ('frail older persons'). Insight into whether home visiting programs for older people with poor health are effective is essential for implementation and future research. An assessment of the methodological quality of the included trials is also presented.

\section{Methods}

\section{Search strategy}

The search for trials until 2001 was based on the included trials from four systematic reviews (Table 1) [1-4]. These reviews consider a total of 30 trials. The systematic review by Ploeg et al. [7] was not included; none of the additional trials in this review were based on home visiting programs. Because the largest review and meta-analysis by Stuck et al. was based on an electronic search until 2001, we decided to continue our database search from this year onwards [3]. On July 11 2007, we searched the following databases: Cinahl, the Cochrane Central Register of Controlled Trials, Embase, Medline and PsycINFO. The fol- lowing terms had to be used in the abstract or title: 'geriatric assessment', 'home visit*', 'health visit*', or 'health screening', in combination with 'prevent*' or 'screen*' (see Additional file 1). Because we were only interested in randomized controlled trials for an older population, we also included in the search the exploded medical subject heading (MeSH) terms 'randomized' and 'aged'; this restricted search with MeSH terms was, however, not possible within all databases. Reference lists from potentially relevant papers were manually searched for additional studies. A search for unpublished data was carried out for studies that had published a (design) article of their home visiting program, but without available outcome data or lacking other information necessary to determine eligibility. No language restrictions were imposed.

\section{Selection}

We included randomized controlled trials examining the effects of home visiting programs for people aged 65 years and over. Based on earlier descriptions, preventive home visits are defined as visits to older people living in the community, which are aimed at multidimensional medical, functional, psychosocial, and environmental evaluation of their problems and resources $[1,3,5]$. This evaluation results in specific recommendations aimed at reducing or treating the observed problems and preventing new ones. Follow-up visits are included for the implementation of the intervention plan.

The target populations were older people with a poor health status based on either subjective (e.g. self-rated health) or more 'objective' measures (e.g. (self-reported) functional impairments, and dependencies in (instrumental) activities of daily living). It has been suggested that higher risk older persons would benefit most from a more-intensive intervention that includes systematic follow-up and coordination as well as more frequent visits [14-16]. If we were to expect benefits for this target population, a more intensive intervention may be a necessary requirement. We therefore decided to include studies with a relatively long and intensive follow-up, that is, when the intervention programs consisted of at least four home visits per year and the duration of the follow-up home visit period lasted 12 months or more; the home visits were to be carried out by health professionals, e.g. nurses or general practitioners. Since we focused on older people with poor health, who mostly suffer from multiple health problems, we excluded studies targeted at people with one specific disease. Studies without available data on health status, service use or cost were also excluded.

\section{Validity assessment}

The quality of the research methods was evaluated using an adaptation of the Cochrane Back Review Group list of 
Table I: Included trials in systematic reviews on home visiting programs

\begin{tabular}{|c|c|c|c|c|c|}
\hline \multirow[b]{3}{*}{ Author(s) } & \multirow[b]{3}{*}{ Year } & Haastregt [I] 2000 & Elkan $[2]^{*} 200 \mathrm{I}$ & Stuck [3] 2002 & Meinck [4]† 2004 \\
\hline & & \multicolumn{4}{|c|}{ Electronic search } \\
\hline & & $1966-1999$ & $1966-1997$ & $|985-200|$ & up to 2003 \\
\hline Luker [48] & 1981 & $x$ & $x$ & & \\
\hline Gunner et al. [49] & 1984 & & & $x$ & $x$ \\
\hline Vetter et al. $[50]^{\ddagger}$ & 1984 & $x$ & $x$ & $x$ & $x$ \\
\hline Hendriksen et al. [5I] & 1984 & $x$ & $x$ & $x$ & $x$ \\
\hline Sorensen et al. [52] & 1988 & $x$ & & $\mathrm{x}$ & $x$ \\
\hline Balaban et al. [33] & 1988 & & $\mathrm{x}$ & & $x$ \\
\hline Carpenter et al. [53] & 1990 & $x$ & & $x$ & $x$ \\
\hline McEwan et al. [54] & 1990 & $x$ & $x$ & $x$ & $x$ \\
\hline Oktay et al. [55] & 1990 & & $x$ & & $x$ \\
\hline Clarke et al. [56] & 1992 & & & $x$ & $x$ \\
\hline Hall [20] & 1992 & $x$ & $x$ & & $x$ \\
\hline Pathy et al. [32] & 1992 & $x$ & $\mathrm{x}$ & $x$ & $x$ \\
\hline Hansen et al. [30] & 1992 & & $x$ & & $x$ \\
\hline Williams et al. [27] & 1992 & & $x$ & & $x$ \\
\hline Vetter et al. [57] & 1992 & $x$ & & $x$ & $\mathrm{x}$ \\
\hline van Rossum et al. $[8,9]$ & 1993 & $x$ & $x$ & $x$ & $x$ \\
\hline Dunn et al. [34] & 1994 & & $x$ & & $x$ \\
\hline Fabacher et al. [58] & 1994 & $x$ & $\hat{x}$ & $x$ & $\hat{x}$ \\
\hline Tinetti et al. [29] & 1994 & $x$ & & $x$ & $x$ \\
\hline Wagner et al. [59] & 1994 & $x$ & & & $x$ \\
\hline Archbold et al. [60] & 1995 & & $x$ & & $x$ \\
\hline Stuck et al. [6II] & 1995 & $x$ & $\mathrm{x}$ & $\mathrm{x}$ & $\mathrm{x}$ \\
\hline Dalby et al. [2I] & 2000 & & & & $x$ \\
\hline Stuck et al. [15] & 2000 & & & $x$ & $x$ \\
\hline van Haastregt et al. $[23,24]$ & 2000 & & & $x$ & $x$ \\
\hline Hebert et al. [62] & 2001 & & & $x$ & $x$ \\
\hline Newbury et al. [63] & 2001 & & & $x$ & $x$ \\
\hline Gill et al. [44] & 2003 & & & & $x$ \\
\hline Yamada et al. [22] & 2003 & & & & $x$ \\
\hline
\end{tabular}

*Evaluates home visiting programs that offer health promotion and preventive care; includes nonrandomized controlled trials.

$\dagger$ Based on the previous reviews with addition of three trials.

$\ddagger$ One study describing two trials.

criteria [17]. Four items were omitted, because these were used as inclusion criteria (random allocation and relevance of outcome measure) or were not applicable to the evaluated interventions (blinding of the participants and care provider). The criteria list consists of five descriptive, two statistical, and eight validity items. Each item was scored ' + ' if the criterion was fulfilled, '-' if the criterion was not fulfilled, and '?' if the information was not provided or was unclear. Scores on validity items ranged from 0 to 8 per trial. Trials with at least four fulfilled validity items were considered to be of 'sufficient methodological quality' [18]; only those were included in the evaluation of the effectiveness. The items were scored independently by two reviewers ( $\mathrm{AB}$ and $\mathrm{PN}$ ). Disagreement was resolved by consensus or a third party (EvR).

\section{Data abstraction}

Titles and abstracts resulting from the database search were independently screened ( $\mathrm{AB}$ and $\mathrm{PK})$. Full papers were obtained for potentially relevant studies. Data from all relevant papers were independently abstracted ( $\mathrm{AB}$ and $\mathrm{PN})$; this included data on characteristics of the home visiting programs and outcomes of the trials. Qualitative data abstraction was performed because of heterogeneity between trials regarding interventions and outcome measures. If information was absent from the original paper, attempts were undertaken to obtain complete information from the authors. Reviewers were not blinded to authors' names or institutions or journal of publication. Disagreement was resolved by consensus or a third party (EvR). 


\section{Results \\ Trial flow}

Eight hundred and forty-four abstracts were identified, of which 234 duplicates were discarded (Figure 1). After screening whether the papers referred to randomized controlled trials that investigated home visiting programs for populations aged 65 years and over, we excluded another 542 abstracts. The remaining potentially relevant papers $(n=68)$ were further screened for population and intervention characteristics. Most papers were excluded because the intervention did not consist of at least four visits per year or the duration of the intervention period was less than 12 months $(n=46)$. Another 14 papers were excluded because the target population did not consist of older people with poor health $(\mathrm{n}=11)$, the interveners were volunteers $(n=2)$, or there were no outcomes available $(n=1)$. Eight trials met the inclusion criteria; six of these have already been described in the previous systematic reviews and two studies were newly added. Design articles had been published of the two new studies; for the trial by van Hout et al. [19] no published outcomes were available and the outcomes from the trial by Bouman et al. [10] had been accepted for publication $[12,13]$. We contacted van Hout $e t$ al. for available data on the results of their study; we received information to complete Tables 2, 3 and 4 (see below), but they could not supply estimates of their data to complete Table 5 (see below), because those were due for publication elsewhere.

\section{Validity assessment}

Table 2 presents the results of the methodological quality assessment of the eight trials meeting the inclusion criteria. The observed sum score on the validity items ranged from 3 to 7 points (out of range $0-8$ points). Only the trial by Hall [20] did not fulfill at least four criteria and was considered to be of insufficient methodological quality; the other seven trials were of sufficient methodological quality. Data on whether co-interventions were avoided or comparable between the intervention and control group, or whether the compliance was acceptable, was often not provided. For three trials the study groups were not similar at baseline $[15,20,21]$. Most papers however reported a concealment of treatment allocation, blinding of the outcome assessor to the intervention and inclusion of an intention-to-treat analysis.

\section{Study characteristics}

Characteristics of six home visiting programs are shown in Table 3. Two trials were not tabulated, because one was of insufficient methodological quality [20] and another presented only a subgroup with poor health from the studied general population of older people $[8,9]$. The targeted populations were people aged 65 years and over with poor self-reported health (in the trials by van Hout $e t$ al. [19] and Bouman et al. [12,13]); with instrumental activ- ities of daily living (IADL) dependencies (in the trial by Yamada et al. [22]); or otherwise with functional impairments (in the trials by Dalby et al. [21], Stuck et al. [15] and van Haastregt et al. $[23,24])$. The trial by Yamada et al. also included a subgroup of older people with poor selfreported health from the original population with IADL dependencies [22]; this subgroup is not tabulated. The mean age of the study populations was mostly between 75-79 years. In one trial, the sample size was relatively small with 73 intervention and 69 control participants [21]. Most trials offered four or five home visits per year, with an intervention duration varying between 12 and 36 months. The mean number of visits was 4.5 [25], 5.1 [22], 7.3 [11], 7.5 [15], and, on average, 18.9 hours (from personal communication with the first author) [21]. The visits were carried out by home or health nurses; in two trials the assessment was done in cooperation with a primary care physician $[19,21]$ and in another trial with a geriatrician [15]. Compliance with the recommendations was reported in half of the trials, varying between $46 \%$ and $65 \%$.

\section{Outcome measures}

None of the trials with sufficient methodological quality showed a significant favorable effect for the main analysis comparing the intervention group with the control group on mortality, health status, service use or cost (Table 4) $[12,13,15,19,21-24]$. For two trials, follow-up of outcome measurements were available at the end of the intervention period and 6 months thereafter $[12,23]$. Van Haastregt et al. found a favorable effect for the intervention group compared to the control group on functional status at the end of the intervention period (12 months), but this effect had disappeared after 18 months of follow-up [23]. None of the other outcomes in this study showed a beneficial effect of the program at 12 or 18 months of follow-up. In the study by Bouman et al. none of the outcomes showed statistically significant differences between the intervention and control group for follow-up measurements at 18 months (the end of the intervention period) or at 24 months [12]. The study by Stuck et al. included a home visit follow-up period of 24 months, but the outcome follow-up was measured at 36 months; no differences in favor of the intervention group compared with the control group were demonstrated [15].

The post hoc subgroup analyses (analyses done after looking at the data) of the trial by van Rossum $[8,9]$ yielded positive effects for intervention participants on several outcome measures, e.g. on health status, IADL, admissions to hospital and homes for older persons, and mortality; the post hoc subgroup analyses of Yamada et al. [22] showed favorable effects for activities of daily living (ADL) and mental health. The one trial of insufficient methodological quality reported a favorable effect for the 
Table 2: Methodological quality of the trials meeting the inclusion criteria

Hall [20] Rossum [8] Dalby [2I] Stuck [15] Haastregt [23] Yamada [22] Hout [19] Bouman [12]

Descriptive items

\begin{tabular}{|c|c|c|c|c|c|c|c|c|}
\hline $\begin{array}{l}\text { I Were eligibility criteria clearly } \\
\text { specified }\end{array}$ & + & + & + & + & + & + & + & + \\
\hline $\begin{array}{l}2 \text { Were index and control } \\
\text { interventions explicitly described }\end{array}$ & + & + & + & + & + & + & + & + \\
\hline $\begin{array}{l}3 \text { Was there a description of } \\
\text { whether adverse effect had or had } \\
\text { not occurred }\end{array}$ & - & + & + & + & + & + & + & + \\
\hline $\begin{array}{l}4 \text { Was a short-term follow-up } \\
\text { measurement (directly after the } \\
\text { intervention) performed }\end{array}$ & + & + & + & - & + & + & + & + \\
\hline $\begin{array}{l}5 \text { Was a long-term follow-up } \\
\text { measurement ( } 6+\text { months after the } \\
\text { intervention) performed }\end{array}$ & - & - & - & + & + & - & - & + \\
\hline
\end{tabular}

Statistical items

\begin{tabular}{|c|c|c|c|c|c|c|c|c|}
\hline $\begin{array}{l}6 \text { Was the sample size for each } \\
\text { group described }\end{array}$ & + & + & + & + & + & + & + & + \\
\hline $\begin{array}{l}7 \text { Were point estimates and } \\
\text { measures of variability presented }\end{array}$ & - & + & + & + & + & + & + & + \\
\hline
\end{tabular}

Validity items

\begin{tabular}{|c|c|c|c|c|c|c|c|c|}
\hline $\begin{array}{l}8 \text { Was treatment allocation } \\
\text { concealed }\end{array}$ & + & + & + & + & + & $?$ & + & + \\
\hline $\begin{array}{l}9 \text { Were groups similar at baseline } \\
\text { regarding age, sex, outcome }\end{array}$ & - & + & - & - & + & + & + & + \\
\hline $\begin{array}{l}\text { I0 Were co-interventions avoided } \\
\text { or comparable }\end{array}$ & $?$ & $?$ & $?$ & $?$ & $?$ & $?$ & $?$ & ? \\
\hline $\begin{array}{l}\text { I I Was compliance acceptable in all } \\
\text { groups }\end{array}$ & $?$ & + & $?$ & $?$ & + & + & $?$ & + \\
\hline $\begin{array}{l}12 \text { Was the outcome assessor } \\
\text { blinded to the intervention }\end{array}$ & + & + & + & + & + & + & + & + \\
\hline $\begin{array}{l}\text { I } 3 \text { Was the withdrawal/dropout rate } \\
\text { acceptable (max of } 20 \% \text { for short- } \\
\text { term follow-up and } 30 \% \text { for long- } \\
\text { term follow-up) }\end{array}$ & - & + & + & + & + & + & - & + \\
\hline $\begin{array}{l}\text { I } 4 \text { Was timing of the outcome } \\
\text { assessment in both groups } \\
\text { comparable }\end{array}$ & + & + & + & + & + & + & + & + \\
\hline $\begin{array}{l}\text { I } 5 \text { Did the analysis include an } \\
\text { intention-to-treat analysis }\end{array}$ & $?$ & + & + & + & + & + & + & + \\
\hline \multicolumn{9}{|l|}{ Sum score validity items } \\
\hline+ & 3 & 7 & 5 & 5 & 7 & 6 & 5 & 7 \\
\hline$?$ & 3 & 1 & 2 & 2 & I & 2 & 2 & I \\
\hline- & 2 & 0 & 1 & I & 0 & 0 & I & 0 \\
\hline
\end{tabular}

Notes: scores +, criterion fulfilled; -, criterion not fulfilled; ?, data not provided or unclear (The results of the study by van Hout et al. have not been published yet; questions 3, 7, 9 and 13 were assessed from unpublished information; questions 10 and II could not be assessed.)

intervention group compared to the control group on nursing home admissions (not tabulated) [20].

For the most commonly measured outcomes shown in Table 4 (functional status, hospital and nursing home admissions, and mortality), more detailed information is provided in Table 5. The data on health status is not shown in this table, because the outcomes were based on a variety of different measurement instruments and these could not be reduced to a common denominator. For patients in the intervention and control group, respectively, means or percentages are presented - with unfavorable outcomes on mortality, functional status, and hospital and nursing home admissions. No further quan- 
Table 3: Characteristics of the included home visiting programs

\begin{tabular}{|c|c|c|c|c|c|c|c|c|}
\hline $\begin{array}{l}\text { Author(s) } \\
\text { Year } \\
\text { Country }\end{array}$ & $\begin{array}{l}\text { Sample } \\
\text { size nr I/C }\end{array}$ & $\begin{array}{l}\text { Health status } \\
\text { participants }\end{array}$ & Mean age & Intervention program* & $\begin{array}{l}\text { Number of } \\
\text { visits per } \\
\text { year }\end{array}$ & $\begin{array}{c}\text { Duration of } \\
\text { interventio } \\
\mathrm{n} \text { in years }\end{array}$ & Intervener & Compliance \\
\hline $\begin{array}{l}\text { Dalby [21] } \\
2000 \\
\text { Canada }\end{array}$ & $73 / 69$ & $\begin{array}{l}\text { self-reported } \\
\text { functional impairment, } \\
\text { or admission to } \\
\text { hospital or } \\
\text { bereavement in the } \\
\text { previous } 6 \text { months }\end{array}$ & 79 & $\begin{array}{l}\text { multidimensional } \\
\text { assessment; a care plan } \\
\text { was developed } \\
\text { together with the } \\
\text { primary care physician }\end{array}$ & $\begin{array}{c}\text { as needed } \\
\text { (mean } 18.9 \\
\text { hours) }\end{array}$ & 1.2 & $\begin{array}{l}\text { primary } \\
\text { care nurse }\end{array}$ & $\begin{array}{l}\text { not } \\
\text { reported }\end{array}$ \\
\hline $\begin{array}{l}\text { Stuck [15] } \\
2000 \\
\text { Switzerland }\end{array}$ & || $6 / 23 \mid$ & $\begin{array}{l}\text { high-risk status based } \\
\text { on six baseline } \\
\text { predictors of } \\
\text { functional } \\
\text { deterioration }\end{array}$ & $82 \dagger$ & $\begin{array}{l}\text { annual } \\
\text { multidimensional } \\
\text { assessment (with } \\
\text { physical examinations); } \\
\text { preventive home visits } \\
\text { in collaboration with } \\
\text { the project team's } \\
\text { geriatricians }\end{array}$ & $\begin{array}{c}4 \text { (mean } \\
\left.7.5^{\dagger}\right)\end{array}$ & 2 & $\begin{array}{l}\text { trained } \\
\text { public } \\
\text { health } \\
\text { nurse }\end{array}$ & $\begin{array}{l}\text { not } \\
\text { reported }\end{array}$ \\
\hline $\begin{array}{l}\text { van } \\
\text { Haastregt } \\
{[23,24]} \\
2000 \\
\text { Netherlands }\end{array}$ & $159 / 157$ & $\begin{array}{l}\text { moderate impairments } \\
\text { in mobility, score } \geq 3 \\
\text { on mobility control } \\
\text { scale of the short- } \\
\text { version sickness } \\
\text { impact profile, or a } \\
\text { history of recent falls } \\
\text { ( } \geq 2 \text { in previous } 6 \\
\text { months) }\end{array}$ & 77 & $\begin{array}{l}\text { multidimensional } \\
\text { assessment with } \\
\text { checklists and use of } \\
\text { guidelines; systematic } \\
\text { home visits }\end{array}$ & $\begin{array}{c}5 \text { (mean } \\
4.5)\end{array}$ & I & $\begin{array}{l}\text { trained } \\
\text { community } \\
\text { health } \\
\text { nurse }\end{array}$ & $\begin{array}{l}46 \% \text { for } \\
\text { referrals } \\
\text { and advice }\end{array}$ \\
\hline $\begin{array}{l}\text { Yamada [22] } \\
2003 \text { Japan }\end{array}$ & $184 / 184$ & $\begin{array}{l}\text { dependent in IADL, } \\
\text { independent in ADL, } \\
\text { and not rating their } \\
\text { health as excellent }\end{array}$ & 79 & $\begin{array}{l}\text { multidimensional } \\
\text { assessment based on } \\
\text { the MDS-HC; } \\
\text { scheduled home visits, } \\
\text { primary objective } \\
\text { human interaction }\end{array}$ & $\begin{array}{c}4 \text { (mean } \\
5.1)\end{array}$ & 1.5 & $\begin{array}{l}\text { trained } \\
\text { public } \\
\text { health } \\
\text { nurse }\end{array}$ & $\begin{array}{l}47 \% \text { for } \\
\text { advice }\end{array}$ \\
\hline $\begin{array}{l}\text { van Hout } \\
\text { [19] } 2005 \\
\text { Netherlands }\end{array}$ & $331 / 320$ & $\begin{array}{l}\text { self-reported health } \\
\text { score in the worst } \\
\text { quartile of at least two } \\
\text { of six COOP- } \\
\text { WONCA charts }\end{array}$ & $\geq 75$ & $\begin{array}{l}\text { multidimensional } \\
\text { assessment with RAl- } \\
\text { HC; systematic home } \\
\text { visits, an individual care } \\
\text { plan was set up } \\
\text { complying with patient } \\
\text { priorities together with } \\
\text { the primary care } \\
\text { practice }\end{array}$ & 5 & 1.5 & $\begin{array}{l}\text { trained } \\
\text { home nurse }\end{array}$ & $\begin{array}{l}\text { not (yet) } \\
\text { reported }\end{array}$ \\
\hline $\begin{array}{l}\text { Bouman } \\
{[10,1 \mid 1] 2007} \\
\text { Netherlands }\end{array}$ & $160 / 170$ & $\begin{array}{l}\text { self-reported poor } \\
\text { health status at } \\
\text { baseline, score } 1-5 \text { on } \\
\text { a scale from I-10 } \\
\text { (very poor-excellent } \\
\text { health) }\end{array}$ & 76 & $\begin{array}{l}\text { multidimensional } \\
\text { assessment with } \\
\text { EasyCare } \\
\text { questionnaire and } \\
\text { checklists; systematic } \\
\text { home visits, individual } \\
\text { plan in agreement with } \\
\text { the older persons }\end{array}$ & $\begin{array}{c}5.3 \text { (mean } \\
7.3 \text { ) }\end{array}$ & 1.5 & $\begin{array}{l}\text { trained } \\
\text { home nurse }\end{array}$ & $\begin{array}{l}65 \% \text { for } \\
\text { referrals } \\
58 \% \text { for } \\
\text { advice }\end{array}$ \\
\hline
\end{tabular}

Notes: I, intervention group; C, control group; ADL, activities of daily living; LTC, Long Term Care; MDS-HC, minimal data set home care; COOPWONCA, COOP functional health assessment charts; RAI-HC, resident assessment inventory home care.

* The control group received usual care.

$\dagger$ Mean over entire group of high-risk and low-risk older persons.

titative data synthesis or pooling was carried out because of the limited number of studies.

\section{Discussion}

Of the eight randomized controlled trials evaluating the effectiveness of intensive home visiting programs for older people with poor health or otherwise with functional impairments, seven were of sufficient methodolog- ical quality according to the predefined standard. Even though nearly all studies were methodologically sound, improvements are still possible in specifying whether cointerventions were avoided or comparable between the intervention and control group, and, for half of the studies, in reporting the compliance with the interventions. The main analysis results from the trials of sufficient methodological quality consistently showed that the 
Table 4: Effects of home visits on the main outcome measures of the included trials

\begin{tabular}{|c|c|c|c|c|c|c|}
\hline Measures & Dalby [2I] & Stuck [15] & van Haastregt $[23,24]$ & Yamada [22] & van Hout [19] & Bouman $[12,13]$ \\
\hline Sample size, I/C & $73 / 69$ & || $6 / 23 \mid$ & $159 / 157$ & $184 / 184$ & $331 / 320$ & $160 / 170$ \\
\hline Followed up, I/C & $59 / 54$ & $82 / 188$ & $120 / 115$ & $160 / 149$ & $215 / 209$ & $139 / 154$ \\
\hline Follow-up, months & 14 & 36 & 12 and 18 & 18 & 18 & 18 and 24 \\
\hline Mortality & O & O & ○ & O & O & O \\
\hline Health status & & & $\bigcirc$ & $\bigcirc$ & O & O \\
\hline Functional status (ADL, IADL) & & $\bigcirc$ & ๑ & $\bigcirc$ & O & $\bigcirc$ \\
\hline Mental health & & & $\bigcirc$ & 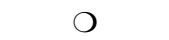 & O & O \\
\hline Social functioning & & & O & & O & O \\
\hline Hospital admission & O & $\bigcirc$ & ○ & & $\bigcirc$ & ○ \\
\hline Nursing home admission & O & O & & & $\mathrm{O}$ & O \\
\hline Home for older persons & & & & & O & O \\
\hline Medical specialist contacts & $\bigcirc$ & O & O & & & $\bigcirc$ \\
\hline GP contacts & $\mathrm{O}$ & $\mathrm{O}$ & 0 & & & $\mathrm{O}$ \\
\hline Home nursing care & & O & O & & O & O \\
\hline Home help & & & O & & $\mathrm{O}$ & O \\
\hline Financial evaluation & & & O & & & $\mathrm{O}$ \\
\hline
\end{tabular}

Notes: I, intervention group; C, control group; ADL, activities of daily living; IADL, instrumental (household) activities of daily living. $\mathrm{O}=$ data available; no statistically significant favorable effect for the intervention group compared to the control group.

- = data available; favorable effect for the intervention group compared to the control group.

* Favorable effect for the intervention group at 12 months of follow-up (end of the intervention), but not at 18 months.

home visiting programs had no effect on the health status or service use of older people with poor health. Based on the information provided in these studies, also no differ- ences were found between the intervention and control group in mortality.

Table 5: Effects of home visits on outcome measures of the included trials for the intervention and control group

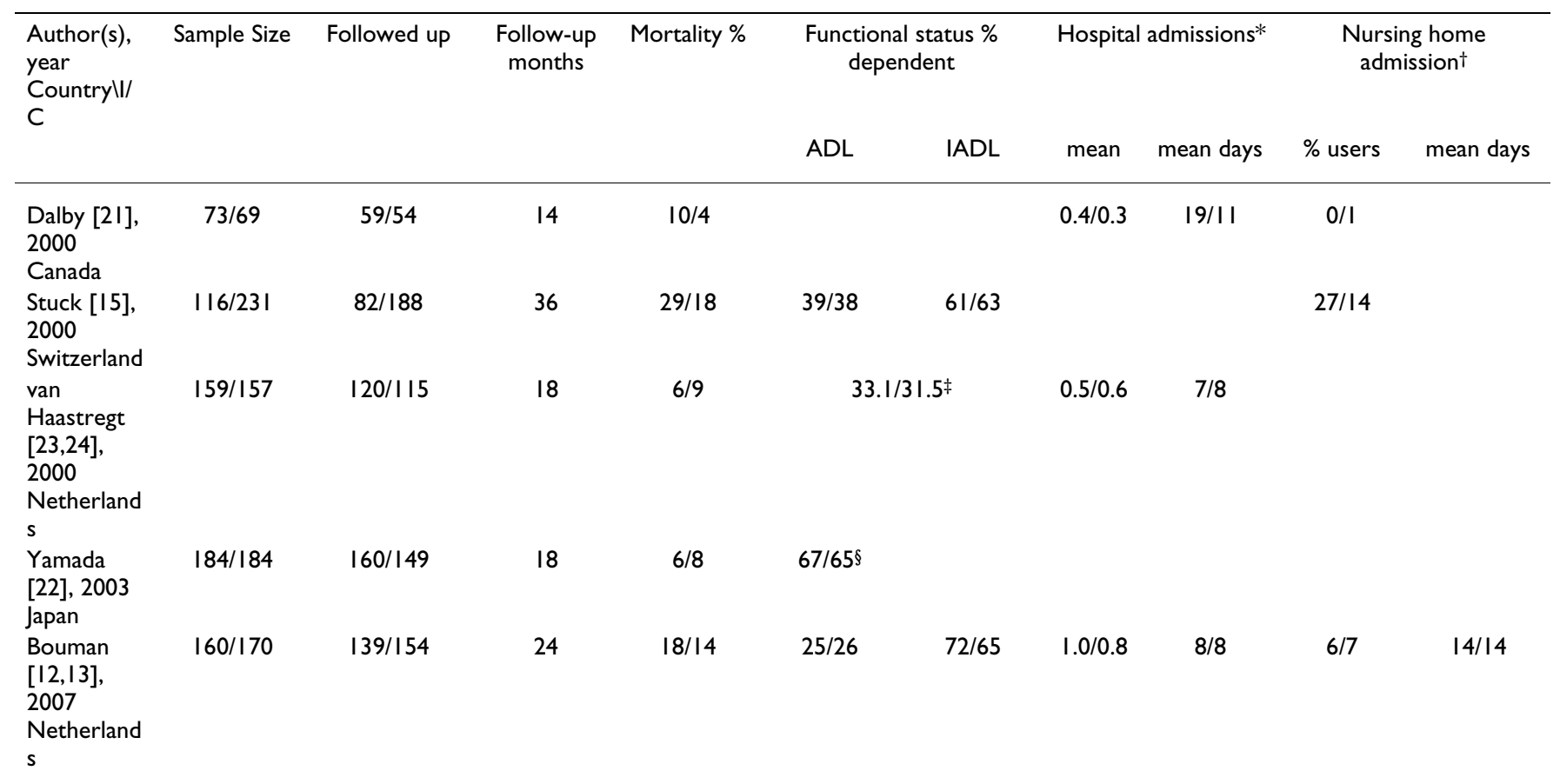

Notes: I, intervention group; C, control group; ADL, activities of daily living; IADL, instrumental (household) activities of daily living.

* Mean number of admissions and length of stay per person in the intervention and control group, respectively, during the follow-up period.

† Mean percentage of users and length of stay per person in the intervention and control group, respectively, during the follow-up period.

‡ Frenchay activities index (scores 13-52, highest score is most favorable).

$\S$ Any problem in usual activities.

(The results from the study by van Hout et al. [19] have not been published yet; the estimates are not available.) 


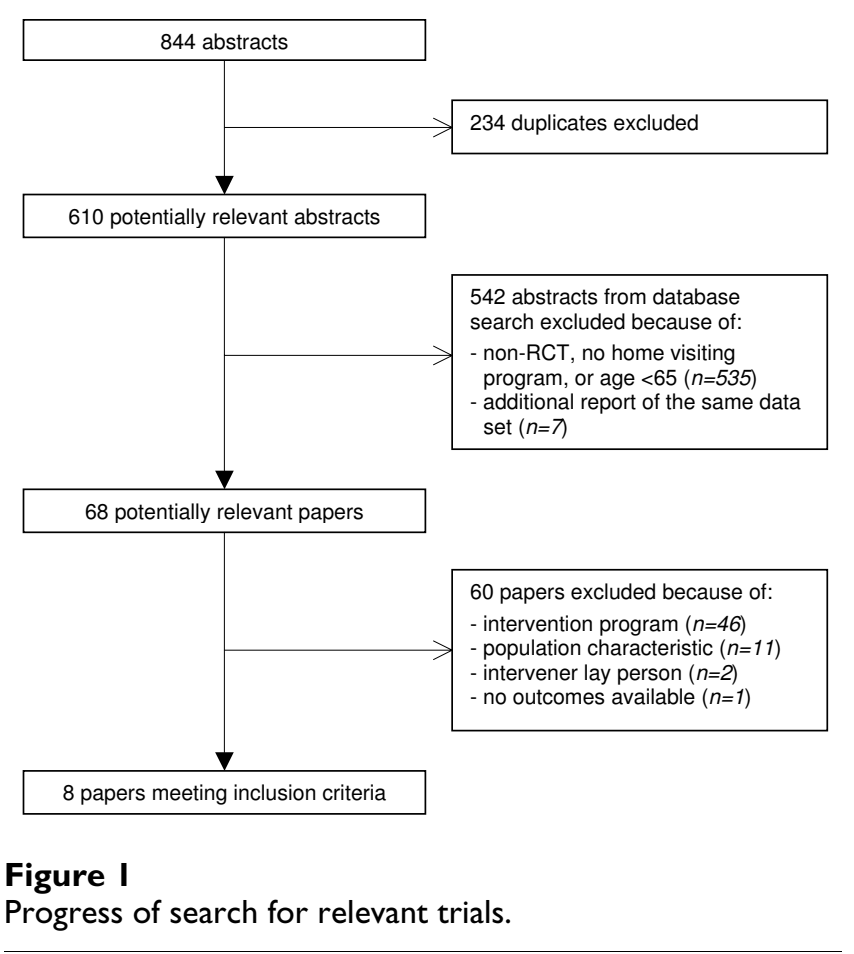

In our evaluation, we did not include the results from the trial of insufficient methodological quality [20] and from post hoc subgroup analyses within two trials $[8,22]$. These studies reported some positive effects, but the results were based on small sample sizes, and, in the trial of insufficient methodological quality, the outcomes may also have been affected by the large drop-out rate and the dissimilarity of the study groups at baseline. The positive effects from the post hoc subgroup comparison from the earlier Dutch study [8] that indicated the visits to be effective for those with a poor perceived health status at baseline could not be confirmed by the results from a larger replication study [12].

The review consists largely of published information; some unpublished data was obtained from two systematically searched studies $[19,21]$. We did not further supplement the database search with expert consultations and it is possible that unpublished data from other trials is available. Studies with significant, positive, results are generally easier to find than those with non-significant or negative results and this could lead to a bias toward a more positive result [26]. Since nearly all studies in our review have negative results, publication bias can not explain the results. To ensure an acceptable standard for design and quality, only randomized controlled trials were included and an assessment of validity items was provided. It is rather striking that the one trial, that provided positive results, was considered to be of poor methodological quality by both reviewers.
In the review by van Haastregt et al. [1] no clear evidence was found in favor of the effectiveness of preventive home visits to older persons. The review and meta-regression analysis by Stuck et al. [3], including 11/15 of the studies from van Haastregt et al. (see Table 1), also showed no effect on mortality, nursing home admissions or functional status. Both reviews included trials with different target populations and interventions. Meta-analytic subgroup analyses in the review by Stuck et al. suggested, however, benefits from home visiting programs for certain types of patients or interventions. For instance, when interventions were targeted at persons with a lower risk for death (defined as annual mortality rates between 3\% and $6 \%$ ), a reduction in functional decline was shown. No reductions were shown for target populations with a mortality rate above $6 \%$. This latter finding is in agreement with the findings in this review, wherein mortality rates were above $6 \%$ in most studies. Meta-analyses in the review by Elkan et al. [2], including 8/15 studies from van Haastregt $e t$ al., also focused on subgroups of frail older persons: no effects were shown on functional status, but positive effects were shown on mortality and nursing home admissions. However, these findings for frail older persons were based on only four studies, including one nonrandomized controlled trial [27] and one we scored in our review as being of insufficient methodological quality [20].

From the search, a number of home visiting programs targeting frail older persons were not included in our review because the intervention consisted of less than four visits per year and/or the duration of the intervention program was shorter than 12 months. The results of studies on lessintensive interventions are mixed. Five studies out of nine showed positive results: two studies with benefits for the intervention group on fall-related outcomes [28,29]; one study showing more nursing home admissions in the control group [30]; one study showing improvements in psychosocial functioning for the intervention group [31]; and one study demonstrating a shorter length of stay at the hospital in the intervention group in the younger group (aged 65-74), but not in the older group (aged 75 or older), and better self-rated health scores in the intervention group (no baseline measurements were available) [32]. Four studies out of nine had negative results [33-36]. As most positive trials (5/9) showed benefits for only one parameter, while the other trials were negative $(4 / 9)$, the overall benefits seem limited. In case we had used different inclusion criteria and added these studies, this would not have exerted a great influence on the findings of our review.

The mean number of visits of the trials presented in Table 3 ranged from 4.5 to 7.5 , and, on average, 18.9 hours; for the non-included studies targeting frail older persons this 
ranged from 1 to approximately 3 [28,30,32-36], with the exception of 7.8 visits in the Tinetti et al. study [29] and a median of 5 visits in the Markle-Reid et al. study [31]. The last two studies were not included, because their intervention period lasted 6 months or less. In general, we succeeded in including studies with more-intensive programs. These did not, however, result in more favorable outcomes for the intervention group compared to the control group. Based on our definition of home visiting programs, all included trials reported a multidimensional assessment with follow-up, also with physical examination in the study by Stuck et al. [15]. Of the less-intensive non-included programs for frail older persons, Hebert et al. [36] and Tinetti et al. [29] included a multidimensional assessment with physical examination. There seemed no apparent relationship between characteristics of the assessments and beneficial effects of the programs.

There is still debate on the frailty concept. The definition and identification of frail older persons varies considerably $[37,38]$. As there is no consensus yet, we used 'poor health status' as inclusion criteria, but we also referred to 'frail older persons'. Because of the wide use in defining frail populations, we decided that the inclusion could be based on either subjective measures (e.g. self-rated health, which is an overall measure for functional health abilities, including physical, mental and social functioning and has shown predictive validity for mortality and institutionalization among older persons $[9,39])$ or on more 'objective' measures (e.g. ADL-scores). Also other measures, e.g. 'at risk for falls' or 'functional impairments', have been described for target populations of frail older persons, and these studies were eligible. The non-included home visiting studies also targeted frail older persons, but did not match our criteria on the intervention program.

The results of the trial by Bouman et al. in the Netherlands have been supported by all methodologically sound studies evaluated in this review [12]. The results from the post hoc subgroup analysis from an earlier Dutch study on which this trial was based, could not be confirmed [8]. The CONSORT statement [40] already made notice of the risk of spurious findings from subgroup analyses [41,42], and indicated that especially post hoc subgroup comparisons are likely not to be confirmed by further studies. This is in line with the findings of this review. Results from reported post hoc subgroup analyses should therefore be interpreted with great caution.

Contrary to our expectation, the findings of this review suggest that intensive home visiting programs targeted at older people with poor health status are not effective. As half of the included studies were carried out in the Netherlands and the other half in other Western countries, the results may only be applicable in comparable health care settings. There seem to be no arguments to add the home visiting program targeting older persons with poor health status to regular healthcare. In a number of countries, e.g. Japan, Denmark and Australia, preventive home visits are part of the national policy and the visits are incorporated into regular healthcare for older persons. It seems essential, that the programs are judged on their merit again when targeting older persons in poor health. The United Kingdom withdrew this policy in 2004 based on the results of a large national trial, which showed that different forms of multidimensional assessment, targeting either the general population of older persons or frail older persons, offered almost no differences in patient outcomes [35].

Frail older persons may benefit from other types of interventions. In a recent editorial by Stuck and Kane, the authors indicated that older persons at higher risk or those already disabled are likely to benefit from multidimensional interventions that target specific problems [43], e.g. favorable effects were shown by a 6-month intensive home-based physical therapy program (16 visits over 6 months) [44], a chronic disease self-management program including three visits and nine telephone calls [45], and by a nurse-centered discharge plan with follow-up home visits for frail older persons discharged from hospital [46]. The economic arguments for these studies remain to be established however. Collaboration between different professionals involved may be necessary to manage the complex care that is often required by frail older persons. In a large European study (11 countries) it was found that home care service based on a case management approach reduced risk of institutionalization in a population of frail older persons in home care [47]. Although care-coordination can be provided by a case-manager, ideally the health and social services should be more integrated and have coordination between the services to supply the best available options for the individual needs of older persons.

\section{Conclusion}

In conclusion, we think that intensive home visiting programs are probably not beneficial for frail older persons within the health care setting of Western countries. Since many older adults prefer to live in their own homes and the population of older adults, including frail adults, is expected to grow, future research is needed to search for alternative approaches to improve the health status of frail older persons.

\section{Competing interests}

The author(s) declare that they have no competing interests. 


\section{Authors' contributions}

EvR and PK developed the original idea. AB performed the search strategy, abstracted data, and drafted the manuscript; PN abstracted data. PK and EvR assisted in the data abstraction process. EvR, GK, PK and PN provided valuable comments during the process of writing this manuscript. All authors read and approved the final manuscript.

\section{Additional material}

\section{Additional file 1}

Search strategies used. Searches used in the databases of Cinahl, Medline, PsycINFO and Embase.

Click here for file

[http://www.biomedcentral.com/content/supplementary/14726963-8-74-S1.doc]

\section{Acknowledgements}

We thank Hein van Hout, VU University Medical Center Amsterdam, the Netherlands and Dawn Dalby, Wilfrid Laurier University, Waterloo, ON, Canada; they provided us with unpublished data.

The review is part of a study funded by ZonMw, the Netherlands Organization for Health Research and Development (Grant 22000 II5), The Hague, the Netherlands. The views expressed are the sole responsibility of the authors. The funding source had no influence on study design; in the collection and interpretation of the data; in the writing of the manuscript; and in the decision to submit the manuscript for publication.

\section{References}

I. van Haastregt JC, Diederiks JP, van Rossum E, de Witte LP, Crebolder HF: Effects of preventive home visits to elderly people living in the community: systematic review. BMJ 2000, 320(7237):754-758.

2. Elkan R, Kendrick D, Dewey M, Hewitt M, Robinson J, Blair M, Williams D, Brummell K: Effectiveness of home based support for older people: systematic review and meta-analysis. British Medical Journal 200I, 323(73 I5):719-725.

3. Stuck AE, Egger M, Hammer A, Minder CE, Beck JC: Home visits to prevent nursing home admission and functional decline in elderly people: systematic review and meta-regression analysis. JAMA 2002, 287(8): I022-1028.

4. Meinck M, Lubke N, Lauterberg], Robra BP: [Preventive home visits to the elderly: systematic review of available evidence]. Gesundheitswesen 2004, 66(I I):732-738.

5. Markle-Reid M, Browne G, Weir R, Gafni A, Roberts J, Henderson SR: The effectiveness and efficiency of home-based nursing health promotion for older people: a review of the literature. Med Care Res Rev 2006, 63(5):531-569.

6. Elkan R, Kendrick D: What is the effectivess of home visiting or homebased support for older people? 2004 [http:// www.euro.who.int/Document/e83105.pdf].

7. Ploeg J, Feightner J, Hutchison B, Patterson C, Sigouin C, Gauld M: Effectiveness of preventive primary care outreach interventions aimed at older people: meta-analysis of randomized controlled trials. Can Fam Physician 2005, 5 I: I 244-I 245.

8. van Rossum E, Frederiks CM, Philipsen H, Portengen K, Wiskerke J, Knipschild P: Effects of preventive home visits to elderly people. BMJ 1993, 307(6895):27-32.

9. van Rossum E: Effects of preventive home visits to the elderly. Maastricht, PhD Thesis Maastricht University; 1993:51-72.

10. Nicolaides-Bouman A, van Rossum E, Kempen GI, Knipschild P: Effects of home visits by home nurses to elderly people with health problems: design of a randomised clinical trial in the Netherlands [ISRCTN920 I7I 83]. BMC Health Serv Res 2004, 4(I):35.

II. Nicolaides-Bouman A, van Rossum E, Habets H, Kempen GI, Knipschild P: Home visiting programme for older people with health problems: process evaluation. J Adv Nurs 2007, 58(5):425-435.

12. Bouman A, van Rossum E, Ambergen T, Kempen G, Knipschild P: Effects of a home visiting programme for older people with poor health status: a randomised clinical trial in the Netherlands. J Am Geriatr Soc 2008, 56(3):397-404.

13. Bouman A, van Rossum E, Evers S, Ambergen T, Kempen G, Knipschild $P$ : Multidimensional geriatric assessment: back to the future effects on health care use and associated cost of a home visiting program for older people with poor health status: a randomized clinical trial in the Netherlands. J Gerontol A Biol Sci Med Sci 2008, 63(3):29I-297.

14. Bula CJ, Berod AC, Stuck AE, Alessi CA, Aronow HU, Santos Eggimann B, Rubenstein LZ, Beck JC: Effectiveness of preventive inhome geriatric assessment in well functioning, communitydwelling older people: secondary analysis of a randomized trial. J Am Geriatr Soc 1999, 47(4):389-395.

15. Stuck AE, Minder CE, Peter Wuest I, Gillmann G, Egli C, Kesselring $A$, Leu RE, Beck JC: A randomized trial of in-home visits for disability prevention in community-dwelling older people at low and high risk for nursing home admission. Arch Intern Med 2000, I 60(7):977-986.

16. Bernabei R, Landi F, Gambassi G, Sgadari A, Zuccala G, Mor V, Rubenstein LZ, Carbonin P: Randomised trial of impact of model of integrated care and case management for older people living in the community. BMJ I998, 3 I 6(7 | 14I): |348-I35|

17. van Tulder MW, Assendelft WJ, Koes BW, Bouter LM: Method guidelines for systematic reviews in the Cochrane Collaboration Back Review Group for Spinal Disorders. Spine 1997, 22(20):2323-2330.

18. van Tulder MW, Cherkin DC, Berman B, Lao L, Koes BW: The effectiveness of acupuncture in the management of acute and chronic low back pain. A systematic review within the framework of the Cochrane Collaboration Back Review Group. Spine 1999, 24( I I): I I I3-I I 23.

19. van Hout HP, Nijpels G, van Marwijk HW, Jansen AP, Van't Veer PJ, Tybout W, Stalman WA: Design and pilot results of a single blind randomized controlled trial of systematic demand-led home visits by nurses to frail elderly persons in primary care [ISRCTN05358495]. BMC Geriatr 2005, 5: I I.

20. Hall N: Randomized trial of a health promotion program for frail elders. Canadian Journal on Aging/La Revue Canadienne du vieillissement 1992, I I(I):72-9I.

21. Dalby DM, Sellors JW, Fraser FD, Fraser C, van Ineveld C, Howard $M$ : Effect of preventive home visits by a nurse on the outcomes of frail elderly people in the community: a randomized controlled trial. CMAJ 2000, I 62(4):497-500.

22. Yamada Y, Ikegami N: Preventive home visits for communitydwelling frail elderly people based on Minimum Data SetHome Care: Randomized controlled trial. Geriatrics and Gerontology International 2003, 3(4):236-242.

23. van Haastregt JC, Diederiks JP, van Rossum E, de Witte LP, Voorhoeve PM, Crebolder HF: Effects of a programme of multifactorial home visits on falls and mobility impairments in elderly people at risk: randomised controlled trial.[comment]. British Medical Journal 2000, 32 I (7267):994-998.

24. van Haastregt JC: Preventing falls and mobility impairments in elderly people living in the community. Maastricht, $\mathrm{PhD}$ thesis Maastricht University; 2002: I35.

25. van Haastregt JC, van Rossum E, Diederiks JP, de Witte LP, Voorhoeve PM, Crebolder HF: Process-evaluation of a home visit programme to prevent falls and mobility impairments among elderly people at risk. Patient Education and Counseling 2002, 47(4):30l-309.

26. Cochrane Handbook for Systematic Reviews of Interventions. Chicester, Wiley; 2005.

27. Williams El, Greenwell J, Groom LM: The care of people over 75 years old after discharge from hospital: an evaluation of timetabled visiting by Health Visitor Assistants. J Public Health Med 1992, I4(2): I 38-144. 
28. Nikolaus T, Bach M: Preventing falls in community-dwelling frail older people using a home intervention team (HIT): results from the randomized Falls-HIT trial. J Am Geriatr Soc 2003, 5 I (3):300-305.

29. Tinetti ME, Baker DI, McAvay G, Claus EB, Garrett P, Gottschalk M, Koch ML, Trainor K, Horwitz RI: A multifactorial intervention to reduce the risk of falling among elderly people living in the community. N Engl J Med I 994, 33 I (I 3):82 I-827.

30. Hansen FR, Spedtsberg K, Schroll M: Geriatric follow-up by home visits after discharge from hospital: a randomized controlled trial. Age Ageing 1992, 2 I(6):445-450.

31. Markle-Reid M, Weir R, Browne G, Roberts ], Gafni A, Henderson S: Health promotion for frail older home care clients. J Adv Nurs 2006, 54(3):38I-395.

32. Pathy MS, Bayer A, Harding K, Dibble A: Randomised trial of case finding and surveillance of elderly people at home. Lancet 1992, 340(8824):890-893.

33. Balaban DJ, Goldfarb NI, Perkel RL, Carlson BL: Follow-up study of an urban family medicine home visit program. Journal of Family Practice 1988, 26(3):307-312.

34. Dunn RB, Lewis PA, Vetter NJ, Guy PM, Hardman CS, Jones RW: Health visitor intervention to reduce days of unplanned hospital re-admission in patients recently discharged from geriatric wards: the results of a randomised controlled study. Arch Gerontol Geriatr 1994, I 8(I): I5-23

35. Fletcher AE, Price GM, Ng ES, Stirling SL, Bulpitt C], Breeze E, Nunes M, Jones DA, Latif A, Fasey NM, Vickers MR, Tulloch AJ: Populationbased multidimensional assessment of older people in UK general practice: a cluster-randomised factorial trial. Lancet 2004, 364(9446): I667-1677.

36. Hebert R, Robichaud L, Roy PM, Bravo G, Voyer L: Efficacy of a nurse-led multidimensional preventive programme for older people at risk of functional decline. A randomized controlled trial. Age Ageing 200I, 30(2): I47-I53.

37. Fried LP, Tangen CM, Walston J, Newman AB, Hirsch C, Gottdiener J, Seeman T, Tracy R, Kop W], Burke G, McBurnie MA: Frailty in older adults: evidence for a phenotype. J Gerontol A Biol Sci Med Sci 200I, 56(3):MI46-56.

38. Markle-Reid M, Browne G: Conceptualizations of frailty in relation to older adults. J Adv Nurs 2003, 44(I):58-68.

39. Idler EL, Benyamini Y: Self-rated health and mortality: a review of twenty-seven community studies. Journal of Health \& Social Behavior 1997, 38(I):21-37.

40. Moher D, Schulz KF, Altman DG: The CONSORT statement: revised recommendations for improving the quality of reports of parallel-group randomized trials. Ann Intern Med 200I, I34(8):657-662.

41. Oxman $A D$, Guyatt $\mathrm{GH}$ : A consumer's guide to subgroup analyses. Ann Intern Med 1992, I I 6:78-84.

42. Pocock S], Hughes MD, Lee RJ: Statistical problems in the reporting of clinical trials. A survey of three medical journals. N Engl J Med I 987, 3 I 7:426-432.

43. Stuck A, Kane RL: Whom Do Preventive Home Visits Help? J Am Geriatr Soc 2007, 56(3):56I-563.

44. Gill TM, Baker DI, Gottschalk M, Gahbauer EA, Charpentier PA, de Regt PT, Wallace SJ: A prehabilitation program for physically frail community-living older persons. Arch Phys Med Rehabil 2003, 84(3):394-404.

45. Phelan EA, Williams B, Penninx BW, LoGerfo JP, Leveille SG: Activities of daily living function and disability in older adults in a randomized trial of the health enhancement program. J Gerontol A Biol Sci Med Sci 2004, 59(8):838-843.

46. Naylor MD, Brooten D, Campbell R, Jacobsen BS, Mezey MD, Pauly MV, Schwartz JS: Comprehensive discharge planning and home follow-up of hospitalized elders: a randomized clinical trial. JAMA 1999, 28 I(7):613-620.

47. Onder G, Liperoti R, Soldato M, Carpenter I, Steel K, Bernabei R, Landi F: Case management and risk of nursing home admission for older adults in home care: results of the AgeD in HOme Care Study. J Am Geriatr Soc 2007, 55(3):439-444.

48. Luker K: Elderly women's opinions about the benefits of health visitor visits. Nurs Times I981, 77( I 2):33-35

49. Gunner Svensson F, Ipsen J, Olsen J, Waldstrom B: Prevention of relocation of the aged in nursing homes. Scand J Prim Health Care 1984, 2(2):49-56
50. Vetter NJ, Jones DA, Victor CR: Effect of health visitors working with elderly patients in general practice: a randomised controlled trial. Br Med J (Clin Res Ed) 1984, 288(64 I 4):369-372.

5I. Hendriksen C, Lund E, Stromgard E: Consequences of assessment and intervention among elderly people: a three year randomised controlled trial. $\mathrm{Br}$ Med J (Clin Res Ed) 1984 289(6457): I522-I524.

52. Sorensen KH, Sivertsen J: Follow-up three years after intervention to relieve unmet medical and social needs of old people. Comprehensive Gerontology Section B, Behavioural, Social \& Applied Sciences 1988, 2(2):85-9|

53. Carpenter GI, Demopoulos GR: Screening the elderly in the community: controlled trial of dependency surveillance using a questionnaire administered by volunteers. BM 1990 , 300(6734): I 253-I 256.

54. McEwan RT, Davison N, Forster DP, Pearson P, Stirling E: Screening elderly people in primary care: a randomized controlled trial.[comment]. British Journal of General Practice 1990 , 40(332):94-97.

55. Oktay JS, Volland PJ: Post-hospital support program for the frail elderly and their caregivers: a quasi-experimental evaluation. Am J Public Health 1990, 80( I):39-46.

56. Clarke M, Clarke SJ, Jagger C: Social intervention and the elderly: a randomized controlled trial. Am J Epidemiol 1992, I36(12): I5I7-1523.

57. Vetter NJ, Lewis PA, Ford D: Can health visitors prevent fractures in elderly people? BMJ 1992, 304(683 I):888-890.

58. Fabacher D, Josephson K, Pietruszka F, Linderborn K, Morley JE, Rubenstein LZ: An in-home preventive assessment program for independent older adults: a randomized controlled trial. J Am Geriatr Soc 1994, 42(6):630-638.

59. Wagner EH, LaCroix AZ, Grothaus L, Leveille SG, Hecht JA, Artz K, Odle K, Buchner DM: Preventing disability and falls in older adults: a population-based randomized trial. Am J Public Health 1994, 84(I I): I800-1806.

60. Archbold PG, Stewart BJ, Miller LL, Harvath TA, Greenlick MR, Van Buren L, Kirschling JM, Valanis BG, Brody KK, Schook JE, et al:: The PREP system of nursing interventions: a pilot test with families caring for older members. Preparedness (PR), enrichment (E) and predictability (P). Res Nurs Health 1995 , I 8(I):3-16.

61. Stuck AE, Aronow HU, Steiner A, Alessi CA, Bula Cl, Gold MN, Yuhas KE, Nisenbaum R, Rubenstein LZ, Beck JC: A trial of annual in-home comprehensive geriatric assessments for elderly people living in the community.[comment]. New England Journal of Medicine 1995, 333( I 8): I I 84- I I 89.

62. Hebert R, Robichaud L, Roy PM, Bravo G, Voyer L: Efficacy of a nurse-led multidimensional preventive programme for older people at risk of functional decline. A randomized controlled trial. Age Ageing 2001, 30(2):147-153

63. Newbury JW, Marley JE, Beilby JJ: A randomised controlled trial of the outcome of health assessment of people aged 75 years and over. Medical Journal of Australia 2001, I75(2):104-107.

\section{Pre-publication history}

The pre-publication history for this paper can be accessed here:

http://www.biomedcentral.com/1472-6963/8/74/prepub 